\title{
Contribuição ao estudo da retificação abrasiva de materiais cerâmicos
}

\section{(Introduction to abrasive grinding of ceramics)}

\author{
H. Fujita ${ }^{1}$ E. C. Bianchi ${ }^{2}$, P. R. de Aguiar ${ }^{2}$ L. E. de A. Sanchez ${ }^{2}$ C. E. da Silva Jr. ${ }^{2}$ \\ ${ }^{1}$ Máquinas Agricolas Jacto $S / A$ \\ R. Dr. Luiz Miranda, 1650, Pompéia, SP 17580-000 \\ ${ }^{2}$ Universidade Estadual Paulista, UNESP \\ Av. Engo Luiz Edmundo Carrijo Coube s/n, Bauru, SP 17033-360 \\ h1bertto@yahoo.com
}

\begin{abstract}
Resumo
Uma das principais limitações relacionadas ao processo de retificação de cerâmica é a confiabilidade do material devido aos defeitos introduzidos no processamento. A compreensão dos mecanismos envolvidos na remoção de material durante a retificação e a interação com os parâmetros de processo e microestrutura é fundamental para minimizar estes defeitos. A proposta desta revisão é apresentar os modelos de remoção de material e a forma como afetam as propriedades mecânicas da peça final.
\end{abstract}

Palavras-chave: cerâmica, diamante, retificação, abrasão.

\begin{abstract}
One of the major restrictions in grinding of ceramics is the probability of failure of material due to the damage induced during the process. The understanding of mechanisms of material removal on grinding and the interaction with the process parameters and microstructure is fundamental to minimize these problems. The purpose of this review is to present the models of material removal in ceramics and the way they affect the mechanical properties of the product.
\end{abstract}

Keywords: ceramics, diamond, grinding, abrasion.

\section{INTRODUÇÃO}

Os custos envolvidos na retificação de cerâmica são amplamente citados na literatura [1-3], como componente principal do custo final de peças cerâmicas de precisão. Assim, a viabilidade econômica e a competitividade de cerâmicas de alto desempenho dependem de forma relevante da eficiência do processo de retificação. A redução do custo de retificação através do aumento da taxa de remoção é limitada pelos danos superficiais e sub-superficiais, que podem comprometer o desempenho da peça durante a aplicação. Além disso, há de se considerar o impacto no custo do processo (vida do rebolo, quantidade de refrigeração etc.).

As taxas de remoção na retificação de materiais cerâmicos variam muito em função da aplicação da peça. Normalmente no meio industrial as taxas de remoção são de aproximadamente um décimo das aplicadas na retificação de metais [4].

A compreensão das propriedades mecânicas dos materiais cerâmicos, dos mecanismos de remoção, dos parâmetros de retificação, bem como das interações entre estas variáveis é fundamental para a otimização do processo de retificação.

O objetivo desta revisão é apresentar o atual estágio do estudo da retificação de materiais cerâmicos.

\section{Propriedades mecânicas das cerâmicas}

Os materiais cerâmicos não apresentam deformação plástica apreciável e sua resistência ao impacto é reduzida, ou seja, apresentam baixa tenacidade. Além disso, é possível encontrar grandes variações de resistência mecânica entre peças de um mesmo lote, podendo ocorrer que a resistência máxima seja o dobro da mínima.

A resistência teórica dos materiais cerâmicos é cerca de vinte a cem vezes maior que os valores obtidos empiricamente [5]. Esta marcante discrepância e a grande variabilidade de valores de resistência mecânica citada anteriormente é explicada pela teoria de Griffith.

A teoria de Griffith considera que um corpo frágil contém pequenas falhas (microtrincas). Quando um esforço de tensão externo é aplicado, as pontas das microtrincas atuam como concentradores de tensão (Fig. 1). Como o corpo não pode liberar estas tensões através de deformação plástica, a tensão local na região próxima à ponta da microtrinca mais severa (crítica) aumenta até atingir a resistência teórica, causando a ruptura do corpo. A equação de Griffith que descreve este processo é:

$$
\sigma=1 / y\left(2 \gamma_{i} E / c\right)^{1 / 2}
$$

na qual $\sigma$ é a tensão de ruptura, $\gamma_{\mathrm{i}}$ é a energia de fratura 


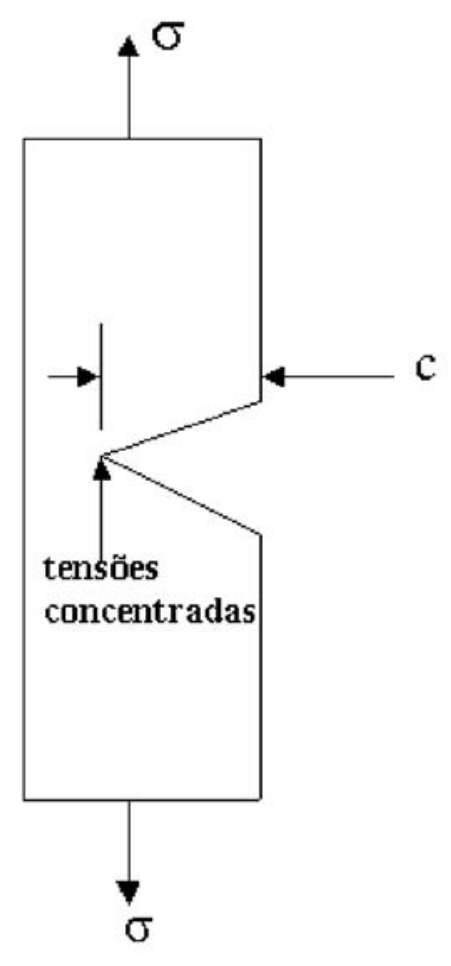

Figura 1: Representação da tensão na ponta de uma trinca.

[Figure 1: Schematic representation of stress at the tip of a microcrack.]

por unidade de área necessária para iniciar a fratura, E é o módulo de Young, c é o tamanho da falha e y é uma constante adimensional que relaciona o tamanho da falha com o tamanho do corpo.

Segundo a teoria de Griffith, a resistência dos materiais cerâmicos é controlada principalmente por duas variáveis: Energia de fratura específica ( $\gamma \mathrm{i}$ ), que é uma propriedade do material sem defeitos e que depende de parâmetros microestruturais (como tamanho de grão); Tamanho do defeito crítico (falha), queé uma característica microestrutural relacionada ao processamento do material.

As falhas podem ser divididas em pré-existentes ou induzidas por tensão. As falhas pré-existentes são compostas por falhas extrínsecas (devido a condições externas, como usinagem e sinterização) e falhas intrínsecas (que dependem das propriedades dos materiais e microestrutura). Quando o material cerâmico tem um pequeno tamanho de grão (ou seja, a falha é maior que o tamanho de grão), o defeito crítico depende somente das condições de retificação. Neste caso, a resistência do material é independente da microestrutura. Quando o tamanho da falha equivale ao tamanho do grão, a resistência não depende mais do processamento, porque o tamanho do maior grão determina o tamanho da falha crítica.

\section{Interação entre abrasivo e peça}

Para entender os mecanismos de remoção na retificação de cerâmicas, os estudos que focam a interação entre o grão e a peça podem ser divididos em [6]: Experimentos baseados na abordagem de mecânica de fratura aplicada a indentação estática; testes de riscamento com ponta única ou multiponto, estendendo-se até experimentos completos de retificação.

A abordagem de mecânica de fratura na indentação descreve a interação de um único grão abrasivo com a peça como um evento de indentação. A indentação permite quantificar a fragilidade de materiais cerâmicos. A relação entre dureza $(\mathrm{H})$ e a tenacidade $(\mathrm{Kc})$ é utilizada como índice da fragilidade. Nesta abordagem o processo de retificação é descrito como um indentador agudo forçado a penetrar na peça na direção normal, enquanto é arrastado na direção lateral. O dano induzido é então idealizado como um sistema de trincas (Fig. 2), onde trincas médias são formadas em posição normal à superfície durante a fase de aplicação da carga e as trincas laterais são desenvolvidas paralelas à superfície na fase de remoção da carga do ciclo de indentação.

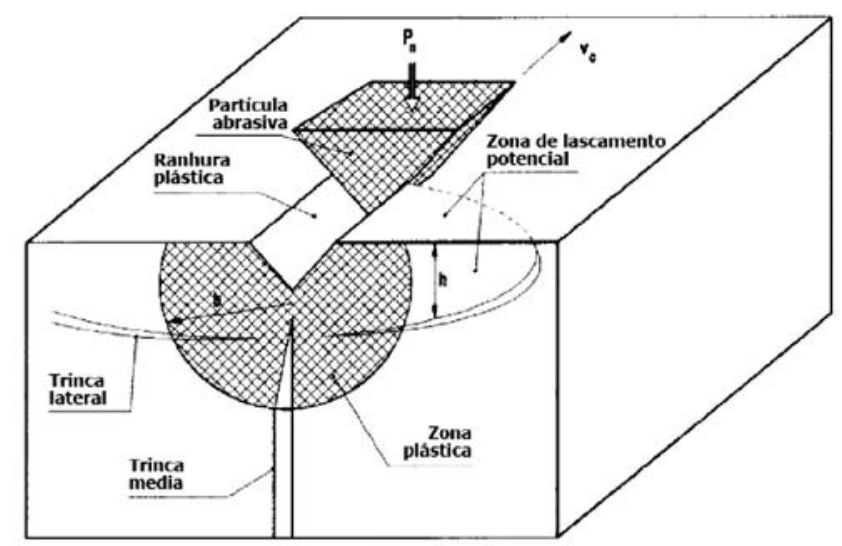

Figura 2: Desenho esquemático da formação de trincas durante riscamento [7].

[Figure 2: Schematic drawing of the formation of cracks during scratching [7].]

As trincas normais (ou médias) que penetram na peça são responsáveis pelos danos residuais durante o processo de retificação, enquanto as trincas laterais são consideradas responsáveis pela remoção de material. A abordagem de indentação é útil para obter informações sobre a evolução das trincas, mas falha na captura de interações e influência dos parâmetros de processo durante a retificação.

A ampliação desta abordagem para testes de riscamento também revela características fundamentais de evolução de trinca. Os testes de riscamento geralmente envolvem medidas de forças de retificação e energia específica junto com observações microscópicas da morfologia da superfície. Essa abordagem permite obter informações sobre as relações entre os mecanismos de remoção e os modos de evolução de danos associados ao processo.

\section{Modelos de remoção de material}

Como os materiais cerâmicos são normalmente muito mais frágeis do que os metais e exibem bem pouca 


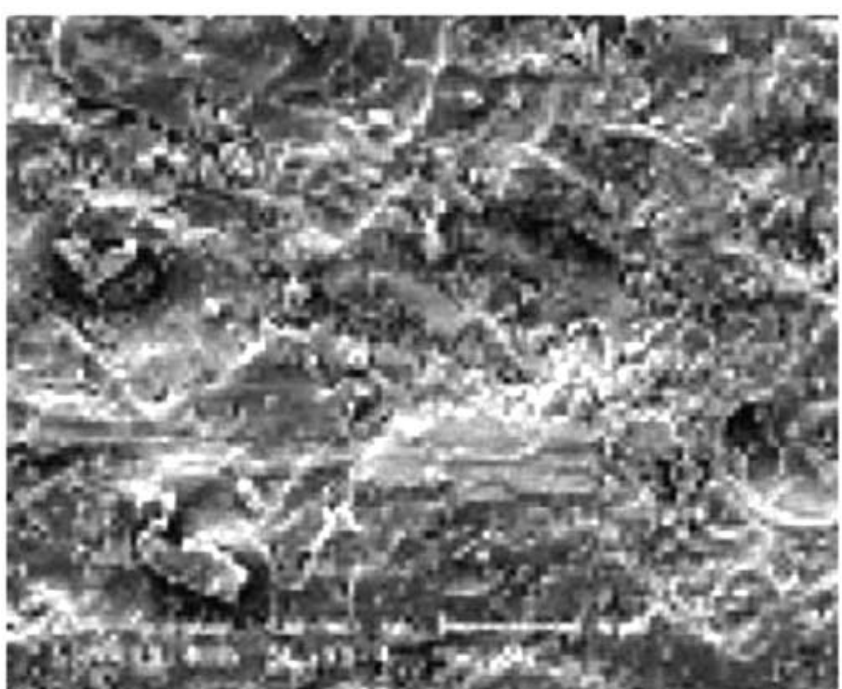

Figura 3: Micrografia de uma superfície retificada de nitreto de silício, apresentando fratura frágil [8].

[Figure 3: SEM micrograph of a ground surface of silicon nitride, showing brittle fracture [8].]

deformação plástica é esperado que os mecanismos de interação entre o abrasivo e a peça envolvam principalmente fratura frágil. A literatura [8,9] (Fig. 3) tem apresentado extensamente exames microscópicos mostrando áreas fraturadas, consistente com o mecanismo de fratura frágil. Contudo, a análise microscópica (Microscopia Eletrônica de Transmissão) de cerâmicas policristalinas retificadas também tem revelado arranjos densos de discordâncias na superfície, evidência inequívoca de fluxo plástico.

A ductilidade de materiais frágeis é observada em testes de indentação e na moagem de pós [10]. O estudo de moagem de partículas indica que conforme o material vai ficando menor ("mais fino"), o mecanismo de redução de tamanho altera-se de fratura para fluxo plástico. A transição do modo frágil para o dúctil pode ser explicada a partir de considerações de energia de remoção de material.

Assim, para menores profundidades de corte, o fluxo plástico é mais favorável energeticamente, sendo caracterizado pela tensão de escoamento $\left(\sigma_{\mathrm{y}}\right)$. A energia $\left(\mathrm{E}_{\mathrm{p}}\right)$ necessária para deformar plasticamente um volume específico de material $\left(\mathrm{V}_{\mathrm{p}}\right)$ pode ser descrita por:

$$
E_{p}=\sigma_{y} \cdot V_{p}
$$

A propriedade de resistência à fratura pode ser descrita pelo parâmetro de propagação de trinca de Griffith (G). A energia $\left(\mathrm{E}_{\mathrm{f}}\right)$ necessária para a fratura é uma função da área $\left(A_{f}\right)$ da nova superfície criada pela propagação da trinca. Assim:

$$
E_{f}=G \cdot A_{f}
$$

Para uma determinada espessura de retificação d, é razoável assumir que a ordem de magnitude de ambos $\mathrm{V}_{\mathrm{p}} \mathrm{e}$
$\mathrm{A}_{\mathrm{f}}$ são determinadas por d. Ou seja:

$$
\begin{aligned}
& V_{p} \sim d^{3} \\
& A_{f} \sim d^{2}
\end{aligned}
$$

A razão entre as energias de remoção de material por deformação plástica (dúctil) e por fratura (frágil) é então proporcionalmente expressa por:

$$
\frac{\text { Energia de fluxo plástico }}{\text { Energia de fratura }} \sim \frac{E_{p}}{E_{f}} \propto d
$$

Consequentemente, conforme a escala de retificação diminui, o fluxo plástico torna-se o mecanismo de remoção de material predominante. A espessura (d) onde ocorre a transição é uma função intrínseca das propriedades dos materiais que controlam a deformação plástica e a fratura.

Para monocristais, a deformação plástica ocorre em planos característicos de deslizamento, enquanto a fratura frágil ocorre em planos característicos de clivagem. Quando uma determinada tensão de cisalhamento aplicada num plano preferencial excede um valor crítico $\tau_{c}$, antes que a clivagem ocorra, uma deformação plástica ocorre em um pequeno campo tensionado do material, com uma escala especificada que pode corresponder à penetração do rebolo na peça. Da mesma forma, a clivagem ocorre quando determinada tensão normal ao plano de clivagem ultrapassa um valor crítico $\sigma_{\mathrm{c}}$, antecedendo a deformação plástica.

A escala de retificação pode ser dividida em três regiões baseadas na densidade de defeitos do material [4]: i) $\mathrm{Na}$ escala de mícron, discordâncias e microtrincas estão presentes no campo tensionado. A tensão crítica $\sigma_{\mathrm{c}}$ diminui conforme a escala de retificação aumenta, pois há maior presença de defeitos no campo tensionado. Por outro lado, a tensão crítica para a deformação plástica $\tau_{c}$ independe destes defeitos. Assim, o modo de remoção frágil é predominante. ii) $\mathrm{Na}$ escala intermediária entre mícron e submícron, a tensão crítica $\sigma_{c}$ não diminui com a redução do tamanho do campo tensionado, porque as microtrincas raramente ocorrem dentro deste campo. Como as discordâncias estão presentes no campo tensionado, a tensão crítica $\tau_{c}$ não apresenta alteração significativa. Assim, o mecanismo de remoção de material tende a mudar de frágil para dúctil. iii) Na região entre submícron e nanômetro, a retificação ocorre numa superfície livre de defeitos, onde a deformação plástica ocorre antes da fratura. Ambos valores de $\tau_{c}$ e $\sigma_{c}$ aumentam até o valor intrínseco de um material perfeito, sendo ocasionalmente afetados pela temperatura ambiente.

As considerações deste argumento resumem a Hipótese de Retificação no Regime Dúctil. Esta hipótese estabelece que se a escala dimensional de retificação de qualquer material for reduzida suficientemente, a remoção se dará por fluxo plástico e não por fratura.

Modelos alternativos e complementares têm sido propostos para a retificação de cerâmicas. A hipótese 


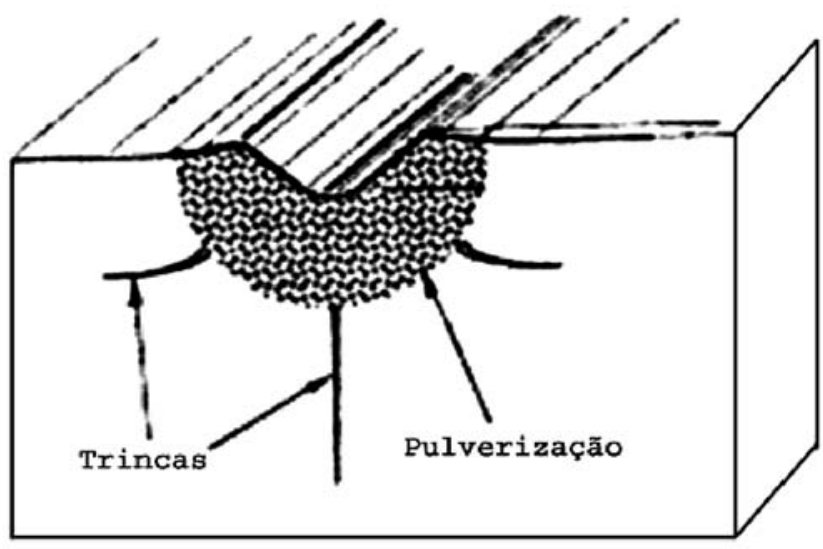

Figura 4: Desenho esquemático ilustrando o modo de remoção por pulverização [4].

[Figure 4: Schematic drawing representing the pulverization mode of material removal [4].]
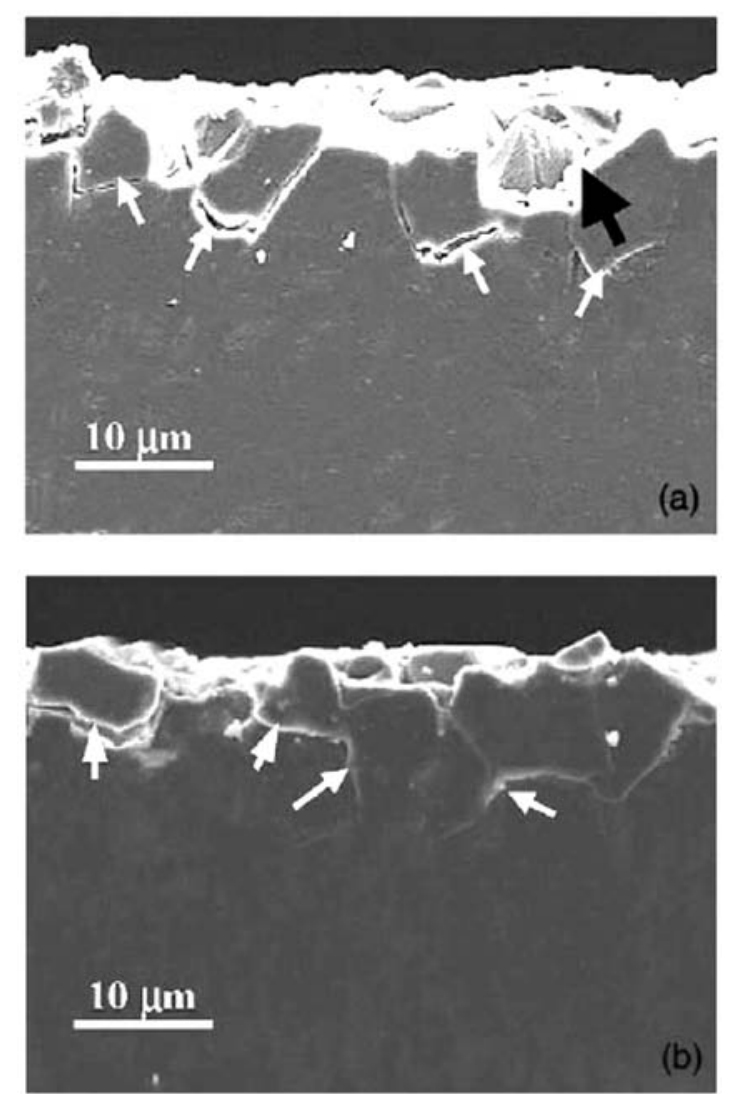

Figura 5: Microtrincas nos contornos de grãos (indicadas pelas setas) devido aos danos causados na retificação [16].

[Figure 5: Micrograps showing microcracks at the grain boundaries (arrows) from grinding induced damage [16].]

do modo de remoção no regime de pó [11] propõe que o mecanismo de remoção de material de cerâmicas retificadas é principalmente devido à pulverização do material, em contraposição à deformação dúctil (Fig. 4). A pulverização [12] seria conseqüência do microtrincamento intergranular e/ou transgranular devido a um campo localizado de tensões superpostas induzidas por grãos abrasivos na retificação. $\mathrm{Na}$ pulverização ou "crushing", os grãos cerâmicos de tamanho micrométrico na região de retificação são pulverizados em grãos de tamanho submicrométricos, formando assim uma camada de pó na superfície retificada.

A microestrutura é um fator crítico na formação e extensão das trincas e consequentemente no modo de remoção de material. Alguns autores [13] afirmam que embora os processos de deformação plástica e remoção por fratura frágil possam ocorrer durante a retificação de cerâmicas policristalinas, o processo de propagação de trincas (com tamanho da ordem de 1-10 $\mu \mathrm{m}$ [14] ) ao longo dos contornos de grãos (microfratura) e remoção de material em escala de grão são mais comuns. O tamanho da zona de microfratura produzida por uma partícula individual de diamante está relacionado com a dureza enquanto a densidade de microtrincas dentro da zona está relacionada à tenacidade do material

\section{Processo de retificação}

O processo de retificação é descrito pela interação de grãos abrasivos na superfície de um rebolo com o material da peça a ser retificada. A microtopografia ativa da superfície dos rebolos é determinada por dois processos: o procedimento de condicionamento para preparação da ferramenta (perfilamento e dressagem) e as alterações da microtopografia durante a retificação. A abrasão, a microfratura (fratura dos grãos abrasivos), a remoção dos grãos abrasivos da liga e a remoção (desgaste) da liga são responsáveis pela alteração na microtopografia do rebolo.

Na retificação de cerâmica o diamante (principalmente sintético) é o abrasivo utilizado, devido a sua dureza e condutividade térmica. Embora seja o material de maior dureza, a dureza do diamante decresce consideravelmente acima de $400{ }^{\circ} \mathrm{C}$ em atmosfera oxidante, pois a rede cristalina do diamante é convertida para a estrutura hexagonal (grafitização).

Há diferentes formas de desgaste do rebolo (Fig. 5). O desgaste nos grãos inicia-se principalmente onde há carga térmica nas regiões externas do grão. Se as temperaturas são muito altas, os diamantes podem ser grafitizados em algumas áreas, que causa considerável redução da resistência ao desgaste. Isto causa o aplainamento ("flattening") do grão abrasivo. $\mathrm{O}$ desgaste devido à abrasão e efeitos térmicos também pode ser causado pelo uso de ligas resistentes ao desgaste com elevada força de retenção de grão (ligas metálicas), pelo emprego de diamantes com alta resistência ao impacto que não microfraturam facilmente e por elevadas velocidades de corte do rebolo.

A microfratura e abrasão ("flattening") dos grãos de diamante são determinadas pelas forças atuantes nas partículas abrasivas. As forças de retificação dependem do tipo de grão, velocidade do rebolo e condições de retificação. Se a carga nos grãos individuais é menor que a força necessária para a fratura parcial do grão, o desgaste ocorre. Isto é observado a altas velocidades. Uma vez este limite atingido, o grão de diamante sai da liga. Este comportamento 


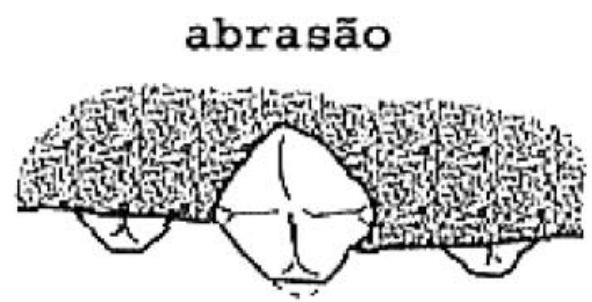

microfratura

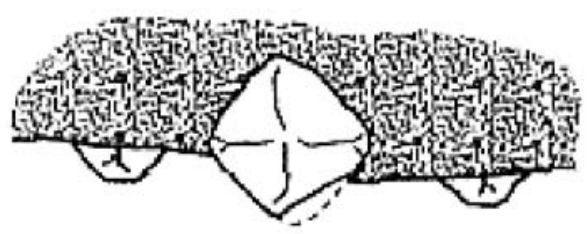

remoção de grão

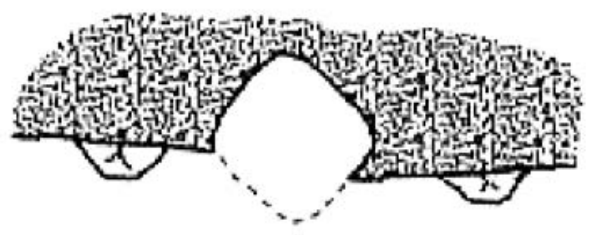

remoção de liga

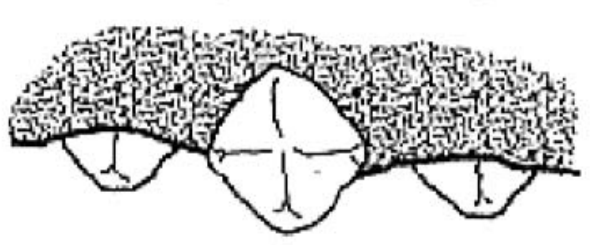

Figura 6: Alterações ocorridas na microtopografia durante a retificação [19].

[Figure 6: Changes occurred in wheel microtopography during grinding process [19].]

de desgaste é observado em menores velocidades de corte.

Conforme o mecanismo de formação do cavaco é crescentemente caracterizado pela fratura frágil, a microfratura do grão predomina. Maiores avanços, junto com altas velocidades do rebolo, mantêm as forças dentro do limite e isto resulta em grande durabilidade [15].

A relação $\mathrm{G}$ é comumente utilizada para caracterizar a durabilidade do rebolo. Ela é definida como a razão entre o volume de material removido da peça e o volume do rebolo desgastado em função desta remoção.

Na retificação a altas velocidades de corte $(40-160 \mathrm{~m} / \mathrm{s})$ de alumina e zircônia $[16,17]$, maiores valores de penetração do rebolo provocaram aumento na relação $\mathrm{G}$ (vida mais longa do rebolo). No mesmo trabalho, o aumento da velocidade de corte do rebolo resultou em ligeiro decréscimo da relação G. De maneira contraditória, [15] em condições semelhantes de retificação (velocidade de corte, taxa de remoção) de alumina e zircônia, outros autores observaram aumento considerável da relação $\mathrm{G}$ com o aumento da velocidade de corte.
Durante a retificação, a taxa de remoção de material (Qw) é determinada pela penetração do rebolo na peça (a), pela velocidade de avanço entre a peça e o rebolo $(\mathrm{Vw})$ e pela largura de retificação (b).

$$
\mathrm{Qw}=\mathrm{a} \cdot \mathrm{Vw} \cdot \mathrm{b}
$$

Dividindo-se a taxa de remoção de material pela largura de retificação, temos a taxa específica de remoção de material:

$$
Q w^{\prime}=a . V w
$$

Esta taxa de remoção pode ser interpretada como uma banda de material que é removida da peça a uma dada velocidade de corte Vs (Fig. 6). A espessura desta banda é chamada de espessura equivalente de corte $\left(\mathrm{h}_{\mathrm{eq}}\right)$, dada por:

$$
\mathrm{h}_{\mathrm{eq}}=\mathrm{a} \cdot \mathrm{Vw} / \mathrm{Vs}
$$

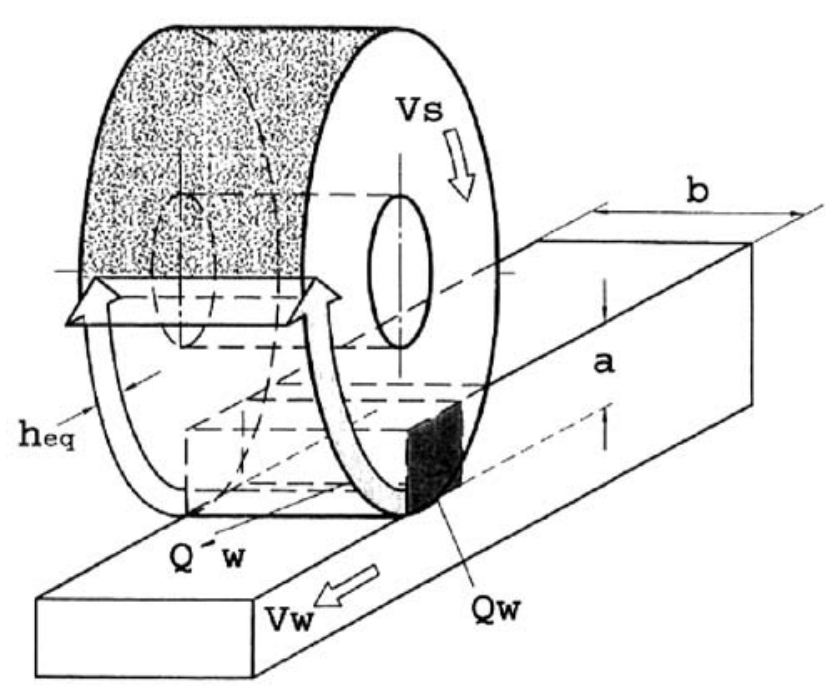

Figura 7: Representação esquemática do processo de retificação [19].

[Figure 7: Schematic drawing of the grinding process [19].]

A profundidade de penetração do grão abrasivo na peça durante a retificação é caracterizada pela espessura máxima do cavaco $\left(\mathrm{h}_{\max }\right)$ :

$$
\mathrm{h}_{\max }=(3 / \mathrm{C} \cdot \tan \theta)^{1 / 2} \cdot(\mathrm{Vw} / \mathrm{Vs})^{1 / 2} \cdot(\mathrm{a} / \mathrm{ds})^{1 / 4}
$$

na qual C é a densidade de arestas de corte ativas e $\theta$ é o ângulo semi-incluso para a seção do cavaco não deformado.

Foi proposto que na retificação de materiais frágeis, um modo de remoção dúctil seria obtido, quando a espessura do cavaco fosse inferior a uma espessura crítica [18]. A espessura crítica do cavaco não deformado (hc) seria dada por:

$$
h c=\beta \cdot(E / H) \cdot(K c / H)^{2}
$$


na qual $\beta$ é uma constante relacionada a topografia do rebolo.

O processo de retificação pode ser caracterizado pela energia específica de retificação, que é a quantidade de trabalho necessária para separar um volume de material do substrato, compreendendo a energia de formação do cavaco, energia de fricção entre os grãos abrasivos e o trabalho e energia dissipados na deformação plástica. A energia específica de retificação( $\mathrm{e}_{\mathrm{c}}$ ) é calculada por:

$$
e_{c}=F t . V s / b . V w . a
$$

na qual Ft é a força de retificação tangencial à circunferência do rebolo.

A energia específica associada com o processo de remoção dúctil de material é muito maior que a obtida no modo frágil devido a energia de fratura de superfície de um material cerâmico ser muito menor que a energia necessária para deformação plástica via cisalhamento e deformação [16].

\section{Danos superficiais e sub-superficiais}

Diferentes regulagens de máquinas e parâmetros de retificação influenciam as propriedades superficiais e subsuperficiais, como tensões residuais, gradientes de tensões, bem como população de microtrincas. O conhecimento detalhado sobre o efeito da retificação na integridade superficial dá oportunidade a uma melhor exploração dos materiais cerâmicos através do aprimoramento das condições de processo.

A técnica de difração de raios $\mathrm{X}$ incorporada ao teste de resistência mecânica à flexão permite determinar a quantidade de danos na cerâmica. Esta técnica é baseada nas informações de deformações plásticas induzidas na retificação e tensões residuais.

Os danos provocados pelo processo de retificação foram identificados por alguns autores [12] como pulverização e microtrincamento. A profundidade dos danos está relacionada com a fragilidade (que é função da tenacidade à fratura e dureza). Sob uma dada condição de retificação, a profundidade de dano será modesta se o material é altamente frágil e será acentuada se for menos frágil. Assim, uma condição de retificação mais agressiva (maior produtividade) pode ser aplicada para tal material. Os autores concluem ainda que a profundidade dos danos aumenta com o tamanho de grão dos rebolos.

Foi observado [13] que embora uma trinca mediana individual ou uma microtrinca possa ser muito pequena para ser crítica na redução de resistência, um grupo de trincas médias ou microtrincas pode atuar como uma trinca maior e iniciar a falha. Uma das implicações de seus resultados é que o espaçamento entre as partículas abrasivas nos rebolos (ditados pela concentração de diamante no rebolo) é um importante parâmetro que poderia influenciar a taxa de remoção e o tamanho das trincas sub-superficiais. Esta prática é baseada em alcançar um grande espaçamento do cavaco que permite o uso de maiores avanços. A desvantagem desta abordagem, contudo, é a possibilidade de aumentar as trincas médias com efeitos danosos na resistência mecânica.
Alguns resultados na retificação de nitreto de silício [19] mostraram que com menores valores de penetração do rebolo (a), obteve-se maiores valores do módulo de Weibull e melhor acabamento. Seus resultados também mostraram que a redução da velocidade de avanço da peça de $0,25 \mathrm{~m} / \mathrm{s}$ para $0,08 \mathrm{~m} / \mathrm{s}$ promoveu uma queda significativa na rugosidade.

A rugosidade superficial pode ser definida como o desvio da superfície geométrica ideal. A escolha de um refrigerante e rebolo abrasivo adequado é de grande importância para a rugosidade. Uma melhoria na rugosidade superficial pode ser alcançada através do uso de rebolos de diamante mais fino, devido ao aumento de deformação plástica.

Alguns pesquisadores [20] relataram que o uso de fluido refrigerante com elevada capacidade térmica e coeficiente de convecção pode provocar uma distorção na camada superficial. $\mathrm{O}$ gradiente das altas temperaturas de retificação para a temperatura ambiente devido à ação do fluido refrigerante causaria tensões térmicas e assim fratura mais frágil, resultando numa superfície mais rugosa.

A microestrutura do material tem grande influência na rugosidade. Cerâmicas que se comportam de uma maneira mais dúctil produzem superfícies de melhor acabamento na retificação. Resultados experimentais [21] na retificação de alumina mostram que a rugosidade decresce com a redução do tamanho médio do grão.

Trabalhos recentes [17] reportaram a redução da rugosidade na retificação de alumina, alumina titânia e zircônia com o aumento da penetração do rebolo na peça. $\mathrm{Na}$ retificação de cerâmica, um aumento da penetração do rebolo normalmente resultaria numa maior força de retificação e por isso prejudicaria o acabamento superficial [18]. Os autores justificam o resultado considerando que o aumento da penetração dificultou a refrigeração, causando um aumento local da temperatura na zona de retificação, amolecendo a superfície da peça e promovendo a retificação dúctil ou reduzindo a tendência à fratura frágil. Seus resultados também mostraram pequena redução na rugosidade com aumento da velocidade de corte.

Na retificação em alta velocidade [18], o aumento da velocidade de corte do rebolo reduz significantemente a máxima espessura do cavaco, $\mathrm{h}_{\max }$, que resulta em menor força de retificação. Porém, no processo de retificação no modo frágil, a rugosidade da superfície retificada não é significantemente influenciada pelo $\mathrm{h}_{\max }$. Contudo, se $\mathrm{h}_{\max }$ ultrapassa um valor crítico, a fratura mudará para um modo de maior escala, (por exemplo, de microfratura para deslocamento de grão). Como resultado, os valores de rugosidade saltam para um nível mais elevado.

\section{CONCLUSÕES}

O modo de remoção de material na retificação de cerâmica depende da escala de retificação, que por sua vez é afetada pela densidade de defeitos da cerâmica. Na escala de micra, o modo de remoção frágil é predominante, de forma que menos energia por volume de material é requerida e assim a retificação pode ser mais vantajosa economicamente. 
Na retificação de cerâmicas policristalinas, os modos de remoção por microfratura nos contornos de grãos e remoção de grãos são mais comuns. Isso implica que a microestrutura pode ser modificada para produzir cerâmicas mais resistentes a danos superficiais e subsuperficiais. A adição de pequena quantidade de fase vítrea, promovendo o alongamento dos grãos (aumento da tenacidade) e enfraquecendo os contornos de grãos resultaria num material com elevada tolerância a danos.

A relação entre as características finais (rugosidade, resistência mecânica) e os parâmetros de processo na retificação de cerâmicas é complexa. O modo de remoção de material define a resposta do material aos parâmetros de processo.

O controle da temperatura na retificação é importante, pois é necessário considerar o comportamento térmico da liga (que provocaria o desprendimento do abrasivo) e a temperatura local na interface peça/diamante, considerando que o diamante sofre uma queda acentuada de dureza acima de $400{ }^{\circ} \mathrm{C}$.

\section{REFERÊNCIAS}

[1] M. Jakobuss, J. Fiecoat, Ceramic Industry 150 (2000) 42.

[2] H. K. Tonshoff, T. Meyer, H. G. Wobker, Ceramic Industry (July 1996) 17.

[3] R. H. Chand, C. Guo, Ceramic Industry 150, 7 (2000) 31.

[4] I. D. Marinescu, H. K. Tonshoff, I. Inasaki, Handbook of Ceramic Grinding and Polishing, Noyes Publications (2000).

[5] E. D. Zanotto, A. R. Migliore, Cerâmica 37 (1991) 247.

[6] G. Subhash, J. E. Loukus, S. M. Pandit, Mechanics of Materials 34 (2002) 25.
[7] A. G. Mamalis, J. Kundrak, K. Gyani, M. Horvath, J. Adv. Manufac. Techn. 20 (2002) 255.

[8] J. Y. Shen, C. B. Luo, W. M. Zeng, Y. S. Gao, J. Mater. Proc. Techn. 129 (2002) 176.

[9] Z. W. Zhong, Int. J. Adv. Manufac. Techn. 21 (2003) 579.

[10] K. L. Blaedel, J. S. Taylor, C. J. Evans, Ductile-Regime Grinding of Brittle Materials, Machining of Ceramics and Composites, Marcel Dekker (1999).

[11] H. P. Kirchner, T. J. Larchuk, J. C. Conway, J. Am. Ceram. Soc. 68, 4 (1985) 20.

[12] B. Zhang, X. L. Zheng, H. Tokura, M. Yoshikawa, J. Mater. Proc. Techn. 132 (2003) 353.

[13] S. Jahanmir, H. K. Xu, L. K. Ives, Mechanisms of Material Removal in Abrasive Machining of Ceramics, Machining of Ceramics and Composites, Marcel Dekker (1999).

[14] H. H. K Xu, S. Jahanmir, L. K. Ives, L. S. Job, K. T. Ritchie, J. Am. Ceram. Soc. 79, 12 (1996) 3055.

[15] K. Ramesh, S. H. Yeo, S. Gowri, L. Zhou, Int. J. Adv. Manufac. Techn. 17 (2000) 87.

[16] H. Huang, Mater. Sci. Eng. A 345 (2003) 155.

[17] H. Huang, Y. C. Liu, Int. J. Mach. Tools \& Manufac. 43 (2003) 811.

[18] H. Huang, L. Yin, L. Zhou, J. Mater. Proc. Techn. 141 (2003) 329.

[19] C. C. Liu, Mater. Sci. Eng. A 379 (2004) 437.

[20] H. K. Toenshoff, T. Lierse, I. Inasaki, "Grinding of advanced ceramics", Machining of Ceramics and Composites, Marcel Dekker (1999).

[21] H. H. K. Xu, L. Wei, S. Jahanmir, J. Am. Ceram. Soc. 79, 5 (1996) 1307.

(Rec. 16/02/2006, Ac. 12/05/2006) 